\title{
Bisnis Informasi Lowongan Kerja: Sebuah Komodifikasi di Portal Media Online dan Jejaring Media Sosial
}

\author{
Qholiva Yuni Fadilla \\ Program Studi Ilmu Komunikasi, Universitas Muhammadiyah Yogyakarta, Indonesia \\ gholivayunifadilla@gmail.com
}

\begin{abstract}
The information society makes the production, processing, distribution and consumption of information the primary economic and social activity. This makes information as one of the main commodities in the information society market industry. LokerJogja.ID as an online media portal and with its social media network makes job content as a marketable commodity and is considered to be able to attract the attention of the public. This study identifies and criticizes how LokerJogja.ID offers commodities in the form of job content to be of appropriate use value. By using a critical paradigm, this study uses virtual ethnography method. Data collected documentation through online media portals and social media networks used by LokerJogja.ID. Then, the findings are analyzed through collection, reduction, and presented in a qualitative-descriptive. Based on the analysis of researchers, online media portals and social networks are only used as a 'container' for profit, that is, by utilizing audiences and content that is sufficiently distributed from job openers. Not only modifying job content as something of exchange value, but LokerJogja.ID has exploited the audience. This relates to the number of audiences as followers and visitors of the online media portal and social network LokerJogja.ID which can affect the profitability of the job content platform.
\end{abstract}

Keywords: Capitalism, Audience, Commodification, Content, LokerJogja.ID.

\begin{abstract}
ABSTRAK
Masyarakat informasi menjadikan produksi, pemrosesan, distribusi, dan konsumsi informasi sebagai kegiatan utama ekonomi dan sosial. Hal ini membuat informasi menjadi sebagai salah satu komoditas utama dalam industri pasar masyarakat informasi. LokerJogja.ID sebagai sebuah portal media online dan dengan jejaring media sosialnya menjadikan konten lowongan kerja sebagai komoditas yang marketable dan dianggap dapat menarik perhatian khalayak. Penelitian ini mengidentifikasi dan mengkritisi bagaimana LokerJogja.ID menawarkan komoditas berupa konten lowongan kerja menjadi sesuai yang bernilai guna. Dengan menggunakan paradigma kritis, penelitian ini menggunakan metode etnografi virtual. Data yang dikumpulkan secara dokumentasi melalui portal media online dan jejaring-jejaring media sosial yang digunakan oleh LokerJogja.ID. Kemudian, temuan dianalisis melalui pengumpulan, reduksi, dan penyajian secara kualitatif-deskriptif. Berdasarkan analisis peneliti, portal media online dan jejaring media sosial hanya digunakan sebagai 'wadah' untuk memperoleh keuntungan yakni, dengan memanfaatkan khalayak dan konten yang cukup didistribusikan dari pembuka lowongan kerja. Tidak hanya memodifikasi konten lowongan kerja sebagai sesuatu yang bernilai tukar, tetapi LokerJogja.ID telah mengeksploitasi khalayak. Hal ini berkaitan dengan jumlah khalayak sebagai pengikut dan pengunjung portal media online dan jejaring media sosial LokerJogja.ID yang dapat mempengaruhi keuntungan platform konten lowongan kerja tersebut.
\end{abstract}

Kata kunci: Kapitalisme, Khalayak, Komodifikasi, Konten, LokerJogja.ID. 


\section{Pendahuluan}

Hari ini, manusia hidup dalam era masyarakat informasi yang menjadikan kegiatan ekonomi bergantung pada produksi dan konsumsi informasi (Straubhaar, LaRose, \& Davenpor, 2012). Masyarakat informasi adalah pandangan manusia mengenai dunia baru dalam membentuk bagian dari kesadaran kontemporer (McQuail, 2009). Aktivitas yang dilakukan oleh masyarakat informasi tak terlepas dari penggunaan media komunikasi digital. Masyarakat informasi menjadikan produksi, pemrosesan, distribusi, dan konsumsi informasi sebagai kegiatan utama ekonomi dan sosial.

Evolusi media dalam masyarakat informasi dapat ditandai dengan teknologi digital yang dijadikan sebagai saluran produksi dan distribusi digital yang lengkap dan end-to-end (Straubhaar, LaRose, \& Davenpor, 2012). Pemanfaatan teknologi ini berdampak pada pesanpesan media massa dengan jangkauan sangat luas (bourderless). Motif yang mendasarinya adalah untuk menyeragamkan selera dan pendapat dengan tujuan memajukan ekonomi industri pasar massal. Adapun bentuk pesan-pesan massa tersebut dapat berupa informasi yang dijadikan sebagai komoditas yang didistribusikan di web dan jejaring media sosial, lalu dikonsumsi oleh masyarakat (Campbell \& Carlson, 2002; Koponen, 2009). Hal ini membuat informasi menjadi sebagai salah satu komoditas utama dalam industri pasar masyarakat informasi.

Komoditas adalah barang atau jasa yang memiliki nilai tukar, sementara komodifikasi merupakan kegiatan kapitalisme ketika menyadari nilai guna memiliki nilai tukar. Komoditas dan komodifikasi merupakan dua hal yang memiliki hubungan objek dan proses. Kedua hal ini menjadi indikator dalam kapitalisme global yang sedang marak terjadi. Komodifikasi adalah salah satu bentuk penguasaan media dalam ekonomi politik media (Mosco, 2009).

"Political economy capture the wide range of approaches to the discipline. In the narrow sense, political economy is the study of the social relations, particularly the power relations, that mutually constitute the production, distribution, and consumption of resources, including communication resources. This formulation has a certain practical value because it calls attention to how the communication business operates" (Mosco, 2009).

Ekonomi politik media mengkaji hubungan sosial, khususnya hubungan kekuasaan yang bersamaan dalam interaksinya menentukan aspek produksi, distribusi, dan konsumsi sumber yang ada. Secara sederhana, ekonomi politik diartikan sebagai hubungan kekuasaan dengan sumber-sumber ekonomi yang ada di masyarakat (Mosco, 2009). Dalam kajian ekonomi politik 
media, konsep komodifikasi menjadi titik awal untuk masuk ke dalam studi ekonomi media kritis. Komodifikasi berasal dari gagasan Karl Marx mengenai sistem kapitalis suatu media yang dapat menjelaskan arah media. Melalui komodifikasi, media mendapatkan keuntungan besar jika memiliki komoditas dengan nilai tukar yang besar (Adila, 2011). Kehadiran komodifikasi dapat membuat produk dari konteks pasar sosial terhapus, sehingga menjadi lebih bermakna dalam bisnis dan ideologi "pasar bebas" (Sumartono, 2016).

Artikel ini fokus untuk membahas komodifikasi konten atau isi media pada portal online lowongan kerja. Berdasarkan perspektif ekonomi politik, konten media (dalam hal ini informasi lowongan kerja) yang disajikan dalam portal media dianggap sebagai komoditas yang memiliki nilai tukar. Khalayak tidak sadar dengan praktik komodifikasi yang dilakukan oleh suatu media dikarenakan khalayak merasa hanya membutuhkan informasi lowongan kerja tersebut. Padahal, informasi lowongan kerja tersebut telah dimodifikasi sehingga menjadi konten yang marketable dan dapat menarik perhatian khalayak (Mosco, 2009).

Sebuah portal lowongan kerja bernama LokerJogja.ID menyajikan komoditas berupa konten untuk membantu para pencari kerja menemukan pekerjaan yang berada di wilayah Daerah Istimewa Yogyakarta. Pada website
LokerJogja.ID, pencari kerja dapat mencari pekerjaan yang sesuai dengan latar belakang pendidikan (SMA/SMK, Sarjana Umum), wilayah penempatan kerja (Kota Jogja, Sleman, Bantul, Gunungkidul, Kulon Progo), dan jam kerja (Full Time, Part Time, Freelance) yang diinginkan. LokerJogja.ID mengklaim bahwa konten yang dimuat di portal berasal dari pembuka lowongan kerja dan menjamin kebenaran informasi yang diberikan.

Gambar 1. Tampilan portal LokerJogja.ID

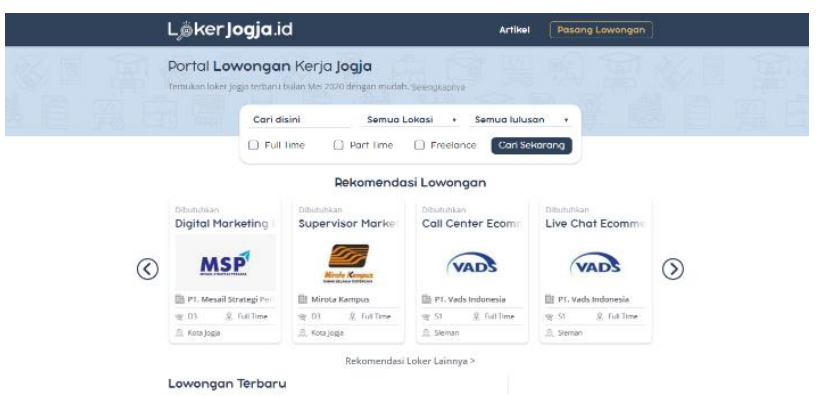

Sumber: Tangkapan layar oleh penulis melalui portal LokerJogja.ID

Berdasarkan paparan di atas, perlu melihat secara kritis bagaimana LokerJogja.ID menawarkan komoditas berupa konten lowongan kerja menjadi sesuatu yang bernilai tukar. Untuk memahami media, diperlukan kata kunci untuk memahami hal mengenai keterkaitan antara media dengan isu konstruksi media (Burton, 2012). Hal ini dikarenakan bisnis media bukanlah hanya sekedar bisnis biasa (McQuail, 2009). 


\section{Metode Penelitian}

Penelitian ini menggunakan paradigma kritis dengan konteks kapitalisme menentukan dan memberi dampak bagi kehidupan masyarakat. Paradigma kritis berupaya untuk memberikan kesadaran dan membebaskan manusia yang berpikir irasional menjadi rasional, sehingga secara kritis mampu mempertanyakan realitas yang sebenarnya (Horkheimer, 1972). Berdasarkan penalaran kritis, produksi konten LokerJogja.ID merupakan realitas hasil konstruksi yang tampak natural dan posisi audiens/khalayak adalah hanya tinggal menerima (taken for granted) informasi lowongan kerja tersebut (Hall, 2003).

Metode dalam penelitian ini menggunakan etnografi virtual atau disebut juga sebagai etnografi siber. Metode ini digunakan untuk melihat fenomena sosial dan kultur di ruang siber (Nasrullah, 2014). Etnografi virtual digunakan sebagai upaya investigasi penggunaan media baru dalam kehidupan masyarakat (Hine, 2000).

Adapun teknik pengumpulan data dilakukan melalui studi dokumentasi secara virtual yang mana peneliti melakukan penelusuran melalui portal media online dan jejaring-jejaring media sosial yang digunakan oleh LokerJogja.ID. Dengan menggunakan metode ini dianggap memungkinkan bagi peneliti untuk melihat konten yang disajikan oleh portal dan jejaring media sosial LokerJogja.ID secara komperhensif. Data temuan dan pembahasan dalam penelitian ini disajikan secara kualitatif-deskriptif. Kemudian, analisis data dalam penelitian ini diolah melalui pengumpulan data, reduksi data, penyajian data, dan penarikan kesimpulan (Miles \& Huberman, 1992).

\section{Hasil Penelitian}

LokerJogja.ID memiliki portal media online dan jejaring media sosial yang digunakan untuk mendistribusikan konten-konten lowongan kerja. LokerJogja.ID menggunakan website sebagai kanal utama yang berisi informasi lengkap mengenai cara dan ketentuan memasang lowongan kerja. Kemudian, LokerJogja.ID juga memiliki tujuh jejaring media sosial yaitu, Website dan Aplikasi LokerJogja.ID, Listing Google Jobs dan Google Bisnis, Instagram @lokerjogjaid, Facebook Loker Jogja ID, Twitter Loker Jogja ID, LinkedIn Loker Jogja ID, dan Telegram @lokerjogjaid.

Beberapa jejaring media sosial LokerJogja.ID seperti LinkedIn, Facebook dan Instagram yang ditelusuri oleh peneliti memuat konten-konten lowongan kerja beserta kualifikasi yang dibutuhkan. LinkedIn memiliki 8.571 pengikut, Facebook memiliki 14.877 yang menyukai dan 15.654 pengikut serta Instagram dengan 5.167 kiriman dan 152.000 pengikut. Beberapa jejaring media sosial yang dimiliki oleh LokerJogja.ID hanya digunakan untuk mendistribusikan konten lowongan kerja. Dengan banyaknya jenis jejaring media sosial yang dimiliki 
LokerJogja.ID, media dengan konten lowongan kerja ini juga memiliki kemungkinan besar untuk mencapai khalayak yang lebih luas dan berskala besar.

Sementara pada portal LokerJogja.ID terdapat pilihan "PASANG LOWONGAN". Hal ini membuktikan bahwa informasi yang tertera di LokerJogja.ID berasal dari lembaga yang membuka lowongan kerja tersebut. Jika pilihan tersebut ditelusuri akan ditemukan informasi terkait memasang lowongan kerja. Pilihan "PASANG LOWONGAN" ini memuat jenis-jenis pilihan paket, biaya paket, ketentuan, tata cara, dan keuntungan memasang informasi lowongan kerja di LokerJogja.ID.

LokerJogja.ID menawarkan tiga jenis pilihan paket untuk memasang informasi lowongan kerja dengan harga dan keuntungan yang berbeda-beda tiap paket.

\section{Gold}

Paket seharga Rp. 200.000,- ini diklaim efektif untuk 10 hari, lebih banyak dilihat, dan konten terletak pada bagian teratas halaman website dan aplikasi. Konten lowongan kerja dengan paket ini akan dipublikasikan lima kali di semua jejaring media LokerJogja.ID dengan tambahan di fitur Instagram pada Highlight Story Favorit.
2. Silver

Paket Silver seharga Rp. 100.000,- ini diklaim efektif untuk 5 hari dan akan dipublikasikan tiga kali di semua jejaring media online LokerJogja.ID.

3. Bronze

Bronze sebagai paket termurah seharga Rp. 50.000,- diklaim efektif untuk 2 hari dan konten dengan paket ini akan dipublikasikan satu kali di semua jejaring media online LokerJogja.ID.

Gambar 2. Paket pasang lowongan di LokerJogja.ID

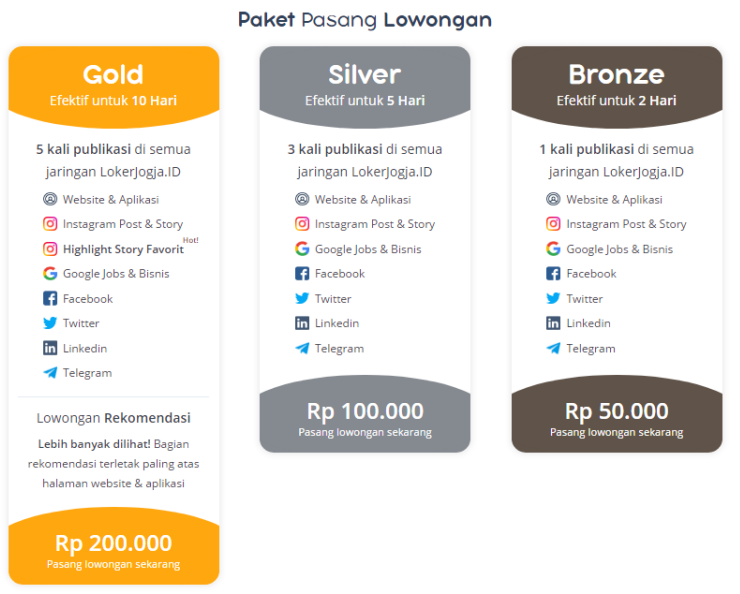

Sumber: Tangkapan layar oleh penulis melalui portal LokerJogja.ID

Seperti paparan di atas, konten lowongan kerja yang dimuat di portal media online dan jejaring media sosial bersumber dari pencari lowongan kerja. Sebutlah sebuah agensi. Agensi membuka lowongan kerja dan akan memasang konten di LokerJogja.ID. Adapun prosedur memasang lowongan kerja di LokerJogja.ID terdiri 
dari empat langkah, yaitu (1) memilih paket, (2) mengirim materi lowongan kerja melalui formulir, (3) melakukan pembayaran, dan (4) publikasi informasi lowongan kerja. LokerJogja.ID mengklaim bahwa jika memasang lowongan kerja akan mendapatkan keuntungan berupa portal dan jejaring media sosial yang dikunjungi ribuan pencari kerja dan diikuti ratusan ribu pencari kerja, serta harga murah dengan fitur maksimal.

Gambar 3. Tata cara dan kelebihan pasang lowongan di LokerJogja.ID

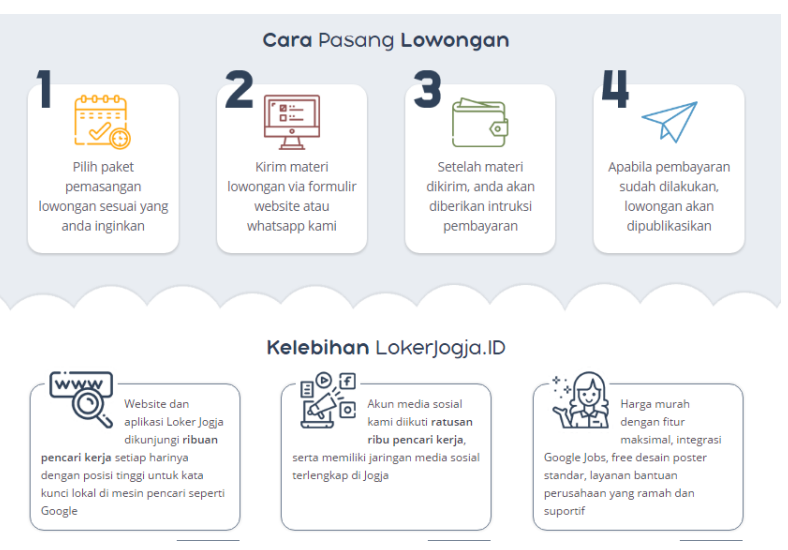

Sumber: Tangkapan layar oleh penulis melalui portal LokerJogja.ID

Selanjutnya, di portal LokerJogja.ID tersedia tiga cara untuk menemukan informasi lowongan kerja yaitu, (1) mencari secara mandiri jenis profesi, lokasi, riwayat pendidikan dan waktu kerja yang diinginkan oleh pencari kerja; (2) Rekomendasi Pekerjaan, menyajikan klasifikasi jenis pekerjaan lengkap dengan nama institusi, profesi, riwayat pendidikan, waktu kerja, dan wilayah bekerja; dan (3) Lowongan Terbaru, sama halnya dengan Rekomendasi Pekerjaan namun bersifat lebih terbaru. Penyediaan tiga jenis cara mencari informasi yang berbeda-beda di portal LokerJogja.ID seolah-olah membuat khalayak merasa diuntungkan. Hal ini dikarenakan khalayak dapat menemukan informasi sesuai keinginan, rekomendasi, atau lowongan terbaru. Ketika salah satu informasi lowongan kerja dipilih, maka akan muncul informasi yang lebih lengkap mengenai deskripsi, syarat, dan mengirim lamaran pekerjaan.

\section{Pembahasan}

Berdasarkan hasil analisis peneliti, konten lowongan kerja sebagai hal yang bernilai guna bagi para pencari kerja dikomodifikasikan oleh LokerJogja.ID untuk menjadi sesuatu yang memiliki nilai tukar. Hal ini yang merujuk pada sebuah praktik kapitalisme. Portal media online dan jejaring media sosial hanya digunakan sebagai 'wadah' untuk memperoleh keuntungan yakni, dengan memanfaatkan khalayak dan konten yang cukup didistribusikan dari pembuka lowongan kerja. Penulis memperkuat pandangan 'wadah' ini melalui temuan yang mana hanya sedikit interaksi antara LokerJogja.ID dengan para pengikut di beberapa jejaring media sosial tersebut. Bahkan, hampir tidak ada feedback yang diberikan oleh LokerJogja.ID atas suatu kiriman konten di jejaring media sosial. Artinya, LokerJogja.ID hanya 'menaruh' konten di ‘wadah' tersebut dan lagi-lagi khalayak hanya mengkonsumsi konten tanpa mengetahui realitas yang sebenarnya. 
Di samping itu, khalayak yang mengkonsumsi konten lowongan kerja di LokerJogja.ID menjadi korban komodifikasi. Hal ini dikarenakan, secara tidak langsung khalayak turut menjadi komoditas dan JogjaLoker.ID memperoleh keuntungan melalui kunjungan khalayak ke portal media tersebut. Dalam konteks ini, khalayak dieksploitasi melalui terciptanya pasar yang secara tidak langsung dimainkan antara LokerJogja.ID dengan pembuka lowongan kerja. Artinya LokerJogja.ID memperlakukan khalayak sebagaimana layaknya produk (komoditas) dimana pihak yang menjual produk adalah sang pemilik portal lowongan kerja, sementara pihak yang membuka lowongan kerja menjadi pembelinya. Portal online sukses dengan hanya melalui jumlah pengunjung atau audiens yang banyak dan sebaliknya portal online akan mengalami kerugian jika jumlah audiens hanya sedikit (Fadillah, 2015). Hal ini berkaitan dengan jumlah pengikut dan pengunjung portal media online dan jejaring media sosial LokerJogja.ID.

Kemudian, LokerJogja.ID mengklaim jika memasang lowongan kerja mendapatkan keuntungan berupa konten yang disajikan di portal dan jejaring media sosial dikunjungi oleh ribuan bahkan ratusan ribu pencari kerja dengan harga pasang yang murah dan fitur maksimal. Situs lowongan kerja ini juga telah menjadikan khalayak sebagai komoditas yang bernilai guna bagi pemasang lowongan kerja. Alih-alih memiliki pengikut dan pengunjung yang banyak di setiap portal media online dan jejaring media sosial, LokerJogja.ID telah menjadikan khalayak sebagai nilai tukar bagi pemasang lowongan kerja. Dengan dijadikannya khalayak sebagai nilai tukar kepada pemasang lowongan kerja, LokerJogja.ID mendapatkan keuntungan melalui pemilihan paket pasang lowongan yang dipertimbangkan oleh suatu agensi yang memasang lowongan.

Sementara itu, pola kerja antara LokerJogja.ID dengan pemasang lowongan kerja hanya sebatas menerima materi - menerima pembayaran paket - mempublikasikan konten. Penulis mengungkapkan hal ini berdasarkan hasil analisis mengenai prosedur memasang lowongan kerja di LokerJogja.ID melalui empat tahapan. Ketika suatu agensi telah menentukan paket pasang lowongan kerja yang ditawarkan LokerJogja.ID, agensi tersebut mengirim materi lowongan, melakukan pembayaran, dan konten terbit. Artinya, di balik kemudahan prosedur memasang lowongan kerja di LokerJogja.ID ternyata ada pola kerja yang sederhana untuk mendapatkan keuntungan besar. Penulis mengibaratkan pola kerja LokerJogja.ID seperti 'memindahkan kue' dari satu wadah ke wadah sebelahnya.

Komodifikasi digambarkan sebagai aksi kapitalisme untuk mengubah nilai guna menjadi nilai tukar (Mosco, 2009). Dalam perspektif ekonomi politik, konten media tidak terlepas dari nilai tukar. Ketika pemilik media memikirkan 
komoditas dalam komunikasi, artinya ada kemungkinan untuk mengawali kegiatan kapitalis dari konten media (Surahman, 2019). Kontenkonten lowongan kerja di LokerJogja.ID dimaksud sebagai komodifikasi isi media dengan tujuan agar informasi lowongan kerja tersebut menjadi sesuatu yang dicari-cari oleh masyarakat. Dengan demikian, terlihat bahwa konten lowongan kerja tersebut menjadi komoditas yang memiliki nilai jual yang tinggi bagi LokerJogja.ID.

Berdasarkan paparan di atas, LokerJogja.ID telah memodifikasi informasi lowongan kerja dengan memanfaatkan komoditas berupa konten dan khalayak. Informasi yang diperoleh dari agensi pemasang lowongan kerja dan memanfaatkan khalayak melalui jejaring media sosial untuk menjadikan nilai guna menjadi nilai tukar. Informasi mengenai lowongan kerja yang seharusnya terbuka untuk umum menjadi komoditas yang diperjualbelikan oleh LokerJogja.ID. Sudut pandang ekonomi politik yang mana nilai jual lebih diutamakan daripada kepentingan umum. Setidaknya pengunjung atau pengikut portal media online dan jejaring media sosial LokerJogja.ID seharusnya menyadari bahwa informasi yang dikonsumsi adalah ladang keuntungan atas aksi kapitalisme. Tidak hanya itu, posisi mereka juga sebagai komoditas dan juga korban komodifikasi.

\section{Penutup}

Berdasarkan analisis yang dilakukan oleh peneliti, LokerJogja.ID melakukan komodifikasi konten dan khalayak untuk membuat ladang keuntungan. Perspektif ekonomi politik media menyatakan bahwa komodifikasi nilai guna menjadi nilai tukar terbukti dalam praktik yang dilakukan oleh LokerJogja.ID. Hal ini sejalan dengan pandangan Mosco (2009) dalam ekonomi politik media mengenai komodifikasi yang digambarkan sebagai aksi kapitalisme untuk mengubah nilai guna menjadi nilai tukar. Tidak hanya itu, Mosco juga memandang bahwa konten media tidak terlepas dari nilai tukar dan hal ini dapat dibuktikan melalui kegiatan LokerJogja.ID. Konten-konten lowongan kerja di media yang seolah-olah sangat dicari-cari oleh para pencari ternyata adalah hasil komodifikasi. Informasi lowongan kerja yang seharusnya terbuka lebar dijadikan konten untuk meraup keuntungan sebesar-besarnya. Kemudian, alih-alih memiliki jejaring media sosial dengan pengunjung dan pengikut yang mencapai angka ratusan hingga ribuan, khalayak secara tidak sadar telah menjadi komoditas yang dijual oleh LokerJogja.ID kepada para pemasang lowongan kerja. Pada akhirnya, khalayak yang dieksploitasi hanya merasa diuntungkan dengan mendapatkan informasi lowongan kerja 
tanpa mengetahui bahwa dirinya telah menjadi komoditas yang menghasilkan rupiah.

\section{Daftar Pustaka}

Adila, I. (2011). Spasialisasi dalam Ekonomi Politik Komunikasi (Studi Kasus MRA Media). Jurnal Ilmu Komunikasi, 1(1), 93-108.

Burton, G. (2012). Media dan Budaya Populer. Yogyakarta: Jalasutra.

Campbell, J., \& Carlson, M. (2002). Panopticon.com: Online surveillance and the Commodification of Privacy. Journal of Broadcasting \& Electronic Media, 46(4), 586-606.

Fadillah, D. (2015). Komodifikasi Seksual dalam Kepentingan Ekonomi Portal Berita Online. INFORMASI Kajian Ilmu Komunikasi, 45(2), 155-162.

Hall, S. (2003). The Work of Representation: "Representation: Cultural Representations and Signifying Practice (Culture, Media and Identities Series). London: Sage Publication.

Hine, C. (2000). Virtual Ethnography. London: Sage Publications.

Horkheimer, M. (1972). Critical Theory: Selected Essays. Translated by Matthew O' Connel et al. New York: Seabury Press.
Koponen, T. J. (2009). Product Review: The War on Democracy. Teaching Sociology, 37(1), 116-118. doi:doi.org/10.1177/0092055X090370 0117

McQuail, D. (2009). Communication Theory. London: Sage Publications.

Miles, M. B., \& Huberman, M. (1992). Analisis Data Kualitatif Buku Sumber Tentang Metode-Metode Baru. Jakarta: UIP.

Mosco, V. (2009). The Political Economy of Communication. London: Sage Publication.

Nasrullah, R. (2014). Teori dan Riset Media Siber (Cybermedia). Jakarta: Kencana.

Straubhaar, J., LaRose, R., \& Davenpor, L. (2012). Media Now: Understanding Media, Culture, and Technology, Seventh Edition. United States of America: Wadsworth Cengage Learning.

Sumartono. (2016). Komodifikasi Media dan Budaya Kohe. Jurnal The Messenger, 8(2), 43-51. doi:http://dx.doi.org/10.26623/themess enger.v8i2.342

Surahman, S. (2019). Komodifikasi Konten, Khalayak, dan Pekerja pada Akun Instagram @salman_al_jugjawy. Nyimak: Journal of Communication, 3(1), 15-29. 